Produto \& Produção, vol. 13 n. 2, p. 40-59, jun. 2012

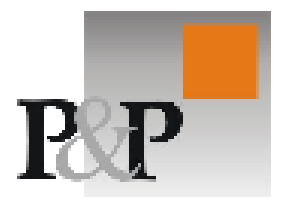

\title{
A formação dos operadores de processos contínuos em contextos de constrangimento da aprendizagem
}

Recebido em 03/11/2011. Aceito em 15/02/2012.

\section{Gilbert Cardoso Bouyer}

Professor Adjunto de Psicologia do Trabalho na UFOP, Campus Joao Monlevade gilbertcb@uol.com.br

O termo desenvolvimento cognitivo é freqüentemente usado em pesquisas ergonômicas. Entretanto, os constrangimentos ("contraintes") da aprendizagem raramente são mencionados. Usando o método da Análise Ergonômica do Trabalho (AET), demonstramos como os operadores aprendem a atividade de controle de processo contínuo, em um contexto de constrangimentos, e demonstramos que a complexidade e os constrangimentos do trabalho influenciam o tempo para o desenvolvimento cognitivo. Apresentamos também aspectos que classificam este tipo de aprendizagem como complexa. Um total de 18 operadores foram entrevistados e observados. Os principais constrangimentos no desenvolvimento dos operadores são: a organização do trabalho e a hierarquia das indústrias de processo contínuo (IPC's). O tempo é um constrangimento porque os operadores têm que aprender o controle de processo em um contexto de tempo curto, com grandes exigências dos gerentes. A aprendizagem das situações reais é urgente, e os operadores têm que lidar com elas rapidamente.

Palavras-Chave: Desenvolvimento cognitivo; Ergonomia; Controle de processo.

The term cognitive development is frequently used in ergonomics research. However, the impediments ("contraintes") of apprenticeship are rarely addressed. Using the method of Ergonomic Work Analysis (EWA), we show how operators to learn the activity of control of continuous process, in the context of impediments, and demonstrating that the complexity and impediments of their work influence the time for the cognitive development. Aspects classifying a type of learning as complex are also presented. The total come to 18 operators who were interviewed and observed. The main impediments in the development of the operators are: the work organization and the hierarchy of the continuous process industry. The time is an impediment because the operators have to learn the process control in a context of a short time, with large exigencies of gerents. The learning of real situations is urgent, so that the operators must to deal with it very quickly.

Keywords: Cognitive development; Ergonomics; Control of process. 


\section{INTRODUÇÃO E PROBLEMA DE PESQUISA}

Este estudo se deparou com um fato intrigante: Os operadores que controlam um processo contínuo de produção (numa indústria de processo contínuo - IPC), por meio de um sistema automatizado de controle de processo contínuo do tipo SDCD (Sistema Digital de Controle Distribuído), levam de dois a quatro anos para adquirirem um desenvolvimento ou aprendizagem (no sentido oferecido por Clot (2006) para a noção de desenvolvimento) suficiente para um controle eficiente do processo. Uma aprendizagem, por natureza, prática e contextualizada (LAVE, 1996).

Este tempo demonstra que a aprendizagem e a aquisição de esquemas de utilização (FOLCHER; RABARDEL, 2004) e saberes necessários ao controle de processo é uma atividade complexa (LEPLAT; TERSSAC, 1990; LEPLAT, 2004, 2008). O controle de processo pode ser visto como uma atividade complexa de gestão de situações dinâmicas (HOC, 2004), as quais evoluem de maneira autônoma e um tanto incerta, devido a fatores não-controláveis. Elas exigem dos operadores o uso de esquemas cognitivos e demais mecanismos adaptativos, em tempo real (LEPLAT; TERSSAC, 1990).

O problema é que esta aprendizagem ocorre em situações de constrangimento ("contrainte"), ou seja, não desfruta de tempo nem de espaço que seriam necessários para o desenvolvimento pleno das capacidades e competências dos operadores (WEILL-FASSINA; PASTRÉ, 2004). Estes constrangimentos geralmente são do tipo temporal e organizacional (LEPLAT, 1997, 1999, 2008).

Indo direto ao problema deste trabalho de pesquisa, verificamos que a atividade dos operadores se inscreve num modelo de atividade mediada e socialmente situada (FOLCHER; RABARDEL, 2004), em que a dimensão social de apropriação cultural dos recursos para uma ação situada eficaz (apropriação de esquemas de utilização, de instrumentos cognitivos) - essência da aprendizagem e do desenvolvimento de competências - é restringida, obliterada, dificultada pelos constrangimentos ("contraintes") temporais e organizacionais criados pela hierarquia das indústrias de processo contínuo (IPC's) e pela organização do trabalho. Não há tempo nem espaço premeditados para a aprendizagem dos operadores, para o seu desenvolvimento cognitivo. Como, então, eles se tornam sujeitos competentes e capazes (RABARDEL; PASTRÉ, 2005), num cenário desfavorável à aprendizagem da complexa atividade de controle de processos nas IPC's?

Em outras palavras, as condições organizacionais e hierárquicas das IPC's dificultam a aprendizagem dos operadores, a sua formação e a complexa aquisição de modelos cognitivos e operativos para a ação situada (FOLCHER; RABARDEL, 2004); dificultam e constrangem também a aquisição de esquemas de utilização (esquemas cognitivos) e a gênese instrumental típica de um sujeito capaz (RABARDEL; PASTRÉ, 2005).

Um sistema automatizado de controle de processo contínuo é um sistema do tipo SDCD (Sistema Digital de Controle Distribuído). Este tipo de sistema é uma interface entre os operadores (que controlam o processo de produção) e o processo produtivo. Os operadores controlam o processo por intermédio do SDCD, que possui sensores, dispositivos de controle, circuitos e válvulas que permitem, pelas telas, teclado e mouse, conhecer o estado do processo (temperatura, pressão, entradas de matérias-primas, saída de produtos acabados, etc.). Embora os operadores fiquem fixos numa sala de controle, equipada com ar condicionado, boa iluminação e 
computadores sofisticados (sob seu controle), eles podem controlar toda a planta industrial, e praticamente todo o processo de produção pelo SDCD.

A modernização dos sistemas de produção, nos últimos quinze anos, pela introdução dos sistemas automatizados de controle de processo, aparece como uma das condições de sobrevivência das IPC's (Indústrias de Processo Contínuo). As indústrias têm, então, buscado utilizar sistemas de controle com desempenho cada vez melhor, o que impacta significativamente no trabalho dos operadores (THIBAULT, 2002).

Torna-se mais proeminente a questão proposta por este estudo o fato de, em nenhuma das IPC's estudadas (duas siderúrgicas, duas mineradoras, uma cimenteira e uma petroquímica) haver um programa premeditado, estruturado e planejado de treinamento e qualificação para os operadores do controle do processo via SDCD.

Ora, como eles aprendem, sem uma política definida de aprendizagem, treinamento e qualificação? Como os operadores adquirem competências para a atividade complexa de controle de processo via SDCD, e como se tornam "sujeitos capazes" (RABARDEL; PASTRÉ, 2005)? Como eles adquirem "esquemas e instrumentos cognitivos, via uma gênese instrumental" (RABARDEL; PASTRÉ, 2005), necessária ao desenvolvimento da formação e da aprendizagem, essenciais para a eficiência do controle automatizado de processo contínuo?

Não para por aí a gravidade e o caráter instigador do problema que tomamos para estudo. Como se não bastasse a ausência de treinamento e de espaço para a aprendizagem, detectamos, nesta pesquisa, que esta ocorre num contexto que ora denominaremos de contexto de constrangimento da aprendizagem. A ergonomia usa, com fartura na literatura, a noção de constrangimentos ("contraintes"), como, por exemplo, em Leplat (1997, 1999, 2008). Constrangimentos, segundo este autor, são espécies de restrições ou impedimentos que o trabalhador deve superar na execução de sua atividade. Como exemplos, temos, citados por Leplat $(1997,1999)$, os constrangimentos temporais (ter que obter resultados num espaço limitado de tempo, e num ritmo que prescreve os modos operatórios, seus tempos e etc.).

Aqui, encontramos e investigamos três tipos principais de constrangimentos da aprendizagem: 1 - constrangimento temporal; 2 - constrangimento organizacional; e 3 - constrangimento relacional.

O constrangimento temporal diz respeito ao curto espaço de tempo que o novo operador dispõe para se tornar um sujeito capaz (RABARDEL; PASTRÉ, 2005). Sob pressões de diferentes naturezas, ele é convidado a aprender e adquirir, e rápido, os conhecimentos, saberes e instrumentos cognitivos (como os esquemas cognitivos, esquemas de utilização e modelos operativos e cognitivos necessários ao trato com o processo, conforme Folcher \& Rabardel, (2004)) para poder assumir, sozinho, a cabine de controle. Ainda, deve responder às demandas do sistema, às informações, avisos e alarmes das telas, deve se antecipar aos imprevistos, sem um tempo suficiente para tal conforme o seu nível de desenvolvimento (ainda prematuro).

O constrangimento organizacional diz respeito aos entraves que a organização do trabalho impõe ao aprendiz (novato). Não há, na organização do trabalho, nem um espaço, nem um horário específico para a aprendizagem e formação do operador, nem um programa planejado de formação ou qualificação para um novo operador.

Por parte dos níveis hierárquicos superiores, responsáveis pela modulação da organização do trabalho, predomina a pressuposição de que o trabalho (complexo) 
dos operadores da cabine de controle é simples. Mas como poderia, ser simples, um trabalho que requer uma aprendizagem de dois a quatro anos para ser bem executado? Na realidade, o trabalho do operador da cabine de controle é complexo, num sentido bem próximo à caracterização de trabalhos complexos oferecida na literatura da ergonomia (VASCONCELOS; LIMA; CAMAROTTO; ABREU; FILHO, 2008; LEPLAT, 2004).

Numa atividade que pode levar até quatro anos para que o operador se torne um sujeito capaz (RABARDEL; PASTRÉ, 2005) - eficiente e competente no controle de processo via SDCD - o operador é deixado à deriva nas malhas prescritivas da organização do trabalho, ficando seu desenvolvimento, sua aprendizagem, sua aquisição de competência, dependentes primordialmente de sua iniciativa e esforço pessoais em buscar, nos interstícios da rígida estrutura hierárquica e organizacional, encontrar brechas ou pequenos espaços para aprender e se tornar um sujeito competente e capaz.

O constrangimento relacional diz respeito à questão social da aprendizagem, no relacionamento com o outro. Aqui, adotamos o ponto de vista de Vygotsky (1996), segundo o qual a aquisição das funções cognitivas superiores, conceitos e instrumentos cognitivos necessários ao aprendizado ocorrem num domínio de interações sociais, no âmbito de uma zona de desenvolvimento proximal (VYGOTSKY, 1996; CLOT, 2006). Ora, mas isso depende da disponibilidade do contexto social em fornecer ao novato as condições para o seu desenvolvimento cognitivo e sua aprendizagem. Essa disponibilidade "social", conforme demonstraram os resultados do presente estudo, é precária em todas as IPC's pesquisadas.

O que encontramos, nas pesquisas de campo, é que o operador novato não dispõe da "boa vontade" de seus pares, de seus colegas já competentes e peritos no controle de processo, para aprender e adquirir a competência necessária para o controle eficiente do processo, via a dimensão da atividade mediada e socialmente situada (FOLCHER; RABARDEL, 2004). Ele fica, segundo expressão de um operador entrevistado, "como um peixe fora d'água, dependendo que os outros me expliquem o que está acontecendo e, na maior parte do tempo, a gente fica boiando, sem entender nada, sem saber o que está acontecendo no processo" (Operador da mineradora).

Um agravante de grande pertinência neste grave contexto de aprendizagem diz respeito ao que é necessário adquirir para se tornar um "expert" no controle de processo e como isso pode ser adquirido. A maior parcela do saber necessário ao controle de processo, por parte do operador, é de caráter tácito e dificilmente formalizado. E a conversão do saber tácito para o saber explícito não ocorre na aprendizagem do operador, na qual se verifica a passagem direta do saber tácito do coletivo para o saber tácito individual do operador, conforme explicações de Jollivet (2003), sem a clássica noção de transmissão de conhecimento de algumas abordagens cognitivistas. Esta aquisição de saber tácito, segundo o autor, é um tanto quanto obscura, e certamente não se enquadra num modelo funcionalista ou cognitivista de transmissão de informação. Ou seja, tornar-se um operador competente e capaz não é absorver informação. O que seria, então? Eis o que buscamos responder neste estudo.

O problema está na natureza do saber necessário ao controle eficiente de processo contínuo. Verificamos que o trabalho prescrito e as suas fórmulas detalhadas na tarefa possuem o seu campo de saberes, em grande parte, já formalizado, repleto de códigos e linguagens epistemologicamente já reconhecidos e 
legitimados (livros, apostilas, gráficos, tabelas, softwares, etc). Mas, nestes dispositivos de saber explícito, formalizado e descritivo, não encontramos o verdadeiro saber tácito responsável pelo controle eficiente do processo produtivo. Este saber está distribuído no coletivo, numa espécie de rede de cognição compartilhada (GALVÃO; SILVA; COCCO, 2003), não estando registrado em lugar algum. É deste saber que o operador necessita se apropriar para se tornar um sujeito capaz e competente.

Verifica-se que os controladores de processo (da cabine de controle) possuem também seus códigos e linguagens, dotados de extrema riqueza, os quais, no entanto, não desfrutam da hegemonia de formalização e elaboração simbólica desfrutados pelo domínio de atuação de outros profissionais, como engenheiros e projetistas (SCHWARTZ, 1998). Logo, a sua aquisição não tem como se dar pela absorção de informações, nem pelo modelo de um treinamento conceitual e teórico, nem pela noção de transmissão de informação. É no contato físico com o coletivo dotado de um saber tácito compartilhado que o operador novato pode adquirir sua expertise. O problema aqui constatado é que a própria organização do trabalho e a rigidez hierárquica ainda predominantes nas IPC's constrangem (dificultam, obliteram) esse desenvolvimento instrumental ou instrumentação (FOLCHER; RABARDEL, 2004) de um operador novato na sua trajetória de desenvolver-se até tornar-se um sujeito capaz instrumentalizado (cognitivamente, possuidor de esquemas operatórios e conceitos) para a ação (RABARDEL; PASTRÉ, 2005).

O saber que o operador deve possuir situa-se no domínio de uma "tacit dimension" (POLANYI, 1983) ou "personal knowledge" (POLANYI, 1998) demandado no trato com as imprevisibilidades, eventos e variabilidades das "situações dinâmicas de trabalho, em tempo real" (HOC, 2004). Este saber não se tem como formalizar facilmente por se tratar de um "know-how" ou saber tácito (JOLLIVET, 2003) não integralmente traduzível em conhecimento explícito, segundo este autor. Ou seja, trata-se, aqui, de uma parcela dos saberes que não há como, em sua totalidade, transmitir, formalizar, simbolizar, sistematizar ou traduzir para a linguagem formalizada, peculiar aos engenheiros e projetistas (SCHWARTZ, 1998). Como adquirir este tipo de saber, em situações de constrangimentos (temporal, organizacional e relacional) de aprendizagem? Os saberes dos operadores, que garantem a sua eficiência, estão na cognição compartilhada dos operadores mais eficientes (JOLLIVET, 2003). Como o novato pode adquirir estes saberes e se tornar um sujeito capaz (RABARDEL; PASTRÉ, 2005), se as condições temporais e organizacionais do trabalho real não são nada favoráveis?

Esses saberes tácitos, boa parte inacessíveis aos códigos e símbolos da linguagem típica do trabalho prescrito, estão enclausurados na cognição compartilhada dos operadores competentes e experientes. Como um novato pode aí penetrar, nesta rede cognitiva compartilhada (GALVÃO; SILVA; COCCO, 2003), de modo a adquiri-los e tornar-se competente no controle de processo contínuo, num contexto que não é favorável à aprendizagem? Por quais mecanismos esses saberes de uma "tacit dimension" (POLANYI, 1983) podem ser adquiridos pelo operador novato? 


\section{MÉTODOS DE PESQUISA}

Nesta pesquisa, foram entrevistados dezoito operadores de cabine, sendo seis da indústria siderúrgica, dois da indústria petroquímica, seis da fábrica de cimento e quatro das empresas mineradoras.

A metodologia deste trabalho se iniciou com o uso de questionário previamente elaborado, num modelo de entrevista semi-estruturada (BECKER, 1997) para, em seguida, aprofundar na experiência de aprendizagem dos operadores segundo os postulados metodológicos da Análise Ergonômica do Trabalho - AET e da "metodologia de ação ergonômica" (DANIELLOU; BÉGUIN, 2004), tendo como ponto de partida este questionário apresentado no Quadro 1 a seguir:

Tabela 1 - Questionário inicial aplicado a 18 operadores das IPC's

1) Há quanto tempo você ocupa o cargo de operador de cabine de controle?

( ) Há menos de 1 ano.

( ) De 1 a 3 anos.

( ) De 3 a 5 anos.

( ) Mais de 5 anos.

2) Se você passou por outras atividades na empresa antes de assumir a de operador de cabine, favor citar quais atividades e o tempo de permanência em cada uma.

3) O quanto você considera importante estas suas experiências anteriores na atividade de controle de processo na cabine?

( ) Essencial.

( ) Muito Importante.

( ) Ajudou, mas não muito.

( ) Não considero importante.

4) Aproximadamente com quanto tempo de serviço na cabine de controle você se sentiu capaz para resolver as situações imprevistas?

( ) Ainda não me sinto seguro.

( ) Com menos de 3 meses.

( ) De 3 a 6 meses.

( ) De 6 meses a 1 ano.

( ) Mais de 1 ano.

5) Você se julga apto para solucionar os problemas que surgem na cabine de controle?

( ) $\operatorname{Sim}$

( ) Não

6) O que faz com que você se sinta capaz para solucioná-los? Enumere de 1 a 4 o que você considera importante, sendo 1 o mais importante e 4 o menos importante.

( ) A experiência que eu adquiri durante meu tempo de trabalho como operador de cabine.

( ) A experiência que eu adquiri trabalhando na área de produção da empresa, em contato com equipamentos, matérias-primas e demais insumos e objetos da produção em situações reais.

( ) O treinamento que eu recebi ao entrar no cargo.

( ) As experiências que meu companheiro de equipe me passou. 
7) Marque 1 para os itens que mais ajudaram você a aprender o seu trabalho e 2 para o que mais faltou para que você aprendesse o seu trabalho. Deixe em branco o que não fez falta alguma.

( ) Passar por um bom treinamento teórico.

( ) A experiência da área; ter trabalhado muito tempo na área.

( ) O tempo e o espaço que me forneceram para ter um contato maior com os operadores que possuíam mais experiência.

( ) O tempo disponível para aprender o controle de processo e a disponibilização da gerência para poder fazer isso.

8)O que foi mais difícil para você aprender o controle de processo da cabine?

9) Quais foram os problemas mais freqüentes na sua aprendizagem do controle de processo?

10) Que conhecimentos da área são importantes no controle da cabine?

11) Quanto tempo demorou para você poder trabalhar sozinho na cabine?

No presente trabalho, adentramos no discurso dos operadores, ao nível de suas experiências cognitivas em atividade de trabalho, conforme o modelo proposto por Leplat (2008). As experiências cognitivas no trabalho são aquelas que não descartam as componentes mais subjetivas da ação, como os aspectos psíquicos, as sensações e as percepções (LEPLAT, 2008; CLOT, 2006). Essas componentes interagem e afetam as componentes cognitivas e, conseqüentemente, os resultados da ação (desempenho, eficiência).

Foram usadas, em larga escala, as entrevistas em "autoconfrontação" (CLOT, 2006), que consistem em oferecer aos operadores, de acordo com o contexto, e no momento da ação, os dados das suas próprias ações (e dos seus comportamentos), ouvindo, no momento presente das mesmas, o que eles têm a dizer a respeito delas.

Ou seja, na autoconfrontação, de acordo com a Análise Ergonômica do Trabalho /AET (DANIELLOU; BÉGUIN, 2004; WISNER, 1987; GUÉRIN et al, 2002), o discurso dos trabalhadores a respeito da atividade de trabalho deve ser mediado pelos dados objetivos da própria atividade. Assim, neste trabalho de pesquisa, as entrevistas em autoconfrontação contribuíram para fornecer um contorno mais nítido e objetivo para as verbalizações dos operadores, aprofundando na investigação das suas experiências concretas de aprendizagem e de formação de competências (WEILL-FASSINA; PASTRÉ, 2004).

O discurso, até certo grau livre, mediado pelo entrevistador e com condições de contorno dadas tanto pelas situações do trabalho quanto pelas vivências no trabalho, muitas vezes, foi regredindo a momentos pretéritos, às vezes longinquamente situados na história de cada operador, em sua atividade, em seu processo de aprendizagem de longos anos. Pode-se, então, dizer que, por permitir elucidar melhor o objeto investigado, via estes resgates de situações vivenciadas no tempo pretérito da trajetória histórica de formação e aprendizagem (na atividade de trabalho) de cada trabalhador, o método da história de vida (BECKER, 1997) não se desprendeu, e não se isolou, do discurso ora desencadeado pelas entrevistas situadas no domínio da autoconfrontação em AET.

Nos métodos de autoconfrontação, segundo a metodologia da AET, procurouse manter o verbo no presente e remeter o sujeito ao seu próprio comportamento, de acordo com aquilo que era observado. A objetividade, a reconstituição minuciosa das situações de trabalho, as observações sistemáticas juntaram-se e buscaram 
conduzir as falas, o discurso, culminando em momentos graves de confrontação daquilo que se dizia com aquilo que se observava e que se tinha, concretamente, numa situação real contextualizada, em tempo real.

\section{ESQUEMAS, CATACRESES E CONSTRANGIMENTOS NA APRENDIZAGEM E NA ATIVIDADE DOS OPERADORES}

Aprender para se formar como um sujeito capaz (RABARDEL; PASTRÉ, 2005) para o controle e a supervisão do processo de produção, por intermédio do SDCD, consiste em adquirir um desenvolvimento cognitivo pelo processo de gênese instrumental ou instrumentação (FOLCHER; RABARDEL, 2004). Neste processo, os estágios de assimilação e acomodação, descritos por estes autores, promovem o desenvolvimento e o enriquecimento dos esquemas cognitivos necessários à complexa atividade de gestão das situações dinâmicas (HOC, 2004).

Os resultados revelam que a aprendizagem para o trabalho de controle de processo na cabine (via SDCD) ocorre por uma reestruturação (POZZO, 2002), num sentido em que a mudança é vista como um processo de duas dimensões: uma, do tipo sujeito-objeto (S-O), e outra, do tipo social - sujeito-sujeito (S-S). A primeira (SO) verifica-se na interação com o processo de produção em dois momentos históricos distintos: 1) desde os tempos de trabalho na área de produção ("chão de fábrica") e 2) na interação com artefatos simbólicos do controle de processo na cabine. A segunda (S-S) verifica-se na apropriação de instrumentos simbólicos (FOLCHER; RABARDEL, 2004), pela dimensão social da atividade, na interação com outros trabalhadores dotados de maior experiência, tanto na época em que trabalhava na área como na cabine de controle.

A aprendizagem produz-se a partir de um desequilíbrio ou um conflito cognitivo, na gênese instrumental, mediante dois processos complementares: a assimilação e a acomodação (FOLCHER; RABARDEL, 2004). Isso fica evidente nos resultados encontrados nas verbalizações dos operadores:

"Eu tenho oito anos de cabine e quinze anos de fábrica. Até hoje surgem coisas novas e problemas que a gente tem que resolver. A gente se vê em dificuldade, mas depois fica fácil. A gente aprende o tempo todo, nunca tem fim... Mas o que facilita muito pra gente aqui é o que a gente aprendeu na área. Eu trabalhei sete anos na área antes de vir pra cabine. Isso foi fundamental para a gente trabalhar bem na cabine" (operador de cabine da siderúrgica).

A assimilação pode ser entendida como a integração de elementos exteriores (como artefatos simbólicos, instrumentos e esquemas) e estruturas em evolução ou já acabadas no sujeito. No presente caso, a assimilação dos esquemas, na época em que o operador trabalhava na área, favorece a acomodação de esquemas novos, necessários ao controle do processo na cabine via SDCD. O sujeito interpreta a informação que provém do meio (que agora é a cabine) em função de seus esquemas ou estruturas conceituais prévias (adquiridas em sua experiência na área externa à cabine). Por exemplo, a categorização conceitual e a gênese instrumental são a assimilação de novos artefatos (simbólicos) aos esquemas de utilização e a acomodação dos esquemas também aos novos artefatos (FOLCHER; RABARDEL, 2004). Na atividade de operador de cabine, um estímulo exterior é assimilado a um esquema que o trabalhador já possua (do seu "tempo de área"), podendo ser assim interpretado como o indício de um defeito, falha de qualidade ou 
incidente, e permitindo-o antecipar-se aos imprevistos e às situações inesperadas ou não-controláveis.

“...sempre há algo novo na cabine. É impossível a gente saber tudo, por que surgem problemas que em oito anos a gente nunca viu. Mas a gente tem que dar conta de resolver" (operador de cabine da siderúrgica).

A aprendizagem do operador de processos contínuos demanda longo tempo, no cerne de uma verdadeira história de desenvolvimento cognitivo verdadeiro desenvolvimento instrumental (RABARDEL; PASTRÉ, 2005) - mobilizado pela aquisição de esquemas operatórios e culminando no uso de catacreses. No topo deste longo processo, temos como resultado a competência para o uso de catacreses essenciais para a manutenção do processo dentro dos padrões exigidos de normalidade.

A ação eficaz é, então, fruto de um desenvolvimento histórico, na qual o sujeito se desvia dos reveses oferecidos pelo real do trabalho (DEJOURS, 1997), os subverte, os burla, numa espécie de criação simbólica que define a junção apropriada entre sujeito e objeto (CLOT, 2006), ao que o autor chama de catacrese:

"O envolvimento dos operadores na ação procura superar os obstáculos que opõem a atividade a si mesma. Ele os leva a duplicar o meio exterior de trabalho mediante um meio técnico pessoal ou coletivo que responde aos dilemas do primeiro. A função do conjunto de ferramentas se vê afetada por uma atividade de reconcepção ou de recriação de técnicas cujo uso é deslocado ou subvertido. Chamamos de catacrese essa atribuição de novas funções às ferramentas, esse uso desviado de uma ferramenta" (CLOT, 2006, p. 181).

Os resultados mostraram que o uso dessas catacreses ocorre na utilização de funções do sistema automatizado, destinadas a um dado objetivo, em um outro objetivo, numa nítida subversão do uso, conforme nos diz Yves Clot. Em outros casos, verificamos que os operadores fazem um uso desviado de uma ferramenta do sistema, com vistas a obter os resultados desejados. Há situações inclusive em que os operadores preferem operar o sistema em manual, desviando e subvertendo completamente as funções padronizadas do sistema de controle de processo:

"A gente aprende a trabalhar bem quando a gente aprende que o sistema não faz tudo certinho. A gente pode aprende a enxergar as falhas dele e a gente tem que tapear o sistema para poder trabalhar direito. A gente tem que driblar o sistema para trabalhar bem e fazer a coisa bem feito. Ele às vezes dificulta o nosso trabalho, mas aí a gente sabe o que tem de ser descumprido no sistema para fazer ele mesmo funcionar direito" (operador da fábrica de cimento).

Ainda, conforme este autor, temos nestes resultados das verbalizações em autoconfrontação, a presença de uma recriação da atividade por parte do sujeito, visto que a atividade de trabalho ultrapassa a própria atividade pela ação criativa e inventiva do operador: trabalhar é recriar.

O desenvolvimento cognitivo é fundamental para que o operador faça uso deste limiar de tolerância, que garante a segurança do sujeito em seu agir, e o permite agir com base em uma liberdade para recriar o seu trabalho, de modo a enfrentar os eventos (imprevistos). Isso se torna possível mediante o uso de esquemas (que levam tempo para se desenvolver). Estes esquemas ampliam a "plasticidade cognitiva" da ação (CLOT, 2006). Segundo o autor, o esquema inicial, percebido como uma recomposição do objeto, pode se incorporar em um esquema mais amplo, dotado de um campo de possibilidades mais vasto.

$E$, mais ainda, pelo recurso da sofisticada noção de catacrese, o sujeito se desprende do trabalho prescrito para agir, com eficácia e eficiência, no real do 
trabalho - aquilo que recua ante as tentativas de simbolização (DEJOURS, 1997), ainda que seja burlando e transformando (recriando) as regras do próprio sistema automatizado para poder alcançar os resultados e objetivos da produção com eficiência.

Quando o operador diz que "tem que driblar o sistema", estamos diante do uso das catacreses descritas por Clot (2006). Para atingir tal nível de desenvolvimento, é preciso passar por anos de aprendizagem.

Os funcionamentos subjetivos e cognitivos do operador seguem a mecanismos de ação que buscam aperfeiçoar as técnicas e instrumentos. Isso demanda expertise e longo tempo de aprendizagem. É preciso ser um perito no controle de processo para utilizar-se destes procedimentos de desvio de objetos (catacreses): por exemplo "tapear o sistema para trabalhar direito" segundo a verbalização do operador.

Vemos então que trabalhar no controle de processo contínuo requer competência (WEILL-FASSINA; PASTRÉ, 2004), desenvolvimento cognitivo para recriar as normas e regras, adaptá-las ao contexto das situações específicas e singulares (segundo a utilização de catacreses). Sem esta atividade catacrética de recriação (e até de subversão), que demanda anos para sua aprendizagem, a atividade de controle de processo via SDCD não atingiria os seus resultados e nem seria eficiente.

\section{A GÊNESE INSTRUMENTAL E A COMPLEXA FORMAC̨ÃO DOS OPERADORES EM CONTEXTOS DE CONSTRANGIMENTO DA APRENDIZAGEM}

Os resultados, não apenas dos questionários, mas principalmente das entrevistas em autoconfrontação, segundo a metodologia da análise e da ação ergonômica (DANIELLOU; BÉGUIN, 2004), revelaram que a grande maioria dos operadores ocupa o cargo de controle do processo contínuo na cabine há mais de cinco anos, conforme mostra o Gráfico 1. Isso indica que se trata de uma atividade complexa, que demanda uma verdadeira história de gênese instrumental ou instrumentação (FOLCHER; RABARDEL, 2004). O tempo de experiência de cabine necessário para controlar o processo ultrapassa, em muito, o período de 1 ano mostrado no Gráfico 2 (questão 4 do questionário: "Aproximadamente com quanto tempo de serviço na cabine de controle você se sentiu capaz para resolver as situações imprevistas?"). Segundo as entrevistas em autoconfrontação, esse tempo situa-se na média de 2 a 4 anos. Mesmo estes operadores mais competentes para a atividade (WEILL-FASSINA; PASTRÉ, 2004) relataram, nas entrevistas, que ainda há dificuldades para lidar com as situações eventuais (imprevistos): "Você ta lá há noves anos e do nada aparece um problema que você nunca deparou com ele antes e se der errado a culpa é de quem?" (operador da indústria Siderúrgica). 


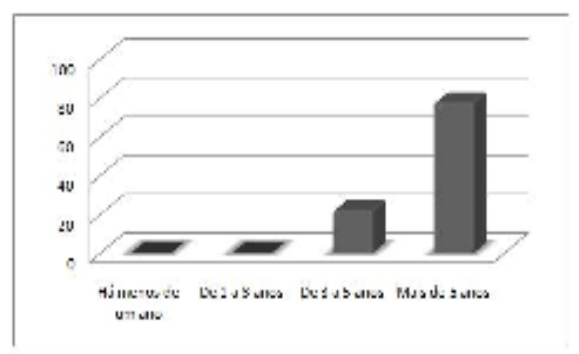

Figura 1 - Tempo de experiência na atividade de controlador de processo contínuo.

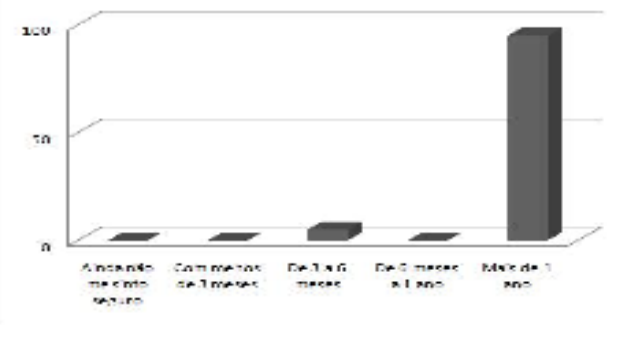

Figura 2 - Tempo de experiência necessário para lidar com situações imprevistas.

Não houve um único operador, que tenha começado a trabalhar como controlador de cabine, que não tenha vivenciado uma longa história de trabalho na área de produção ("chão de fábrica"), em contato com as matérias-primas, equipamentos e demais insumos e objetos da produção, ou seja, com o "real" concreto do processo de produção. Isso se revelou, conforme já explicado anteriormente, como fundamental para a aquisição dos esquemas necessários ao controle do processo via sistema automatizado, e para o uso essencial das catacreses (CLOT, 2006), que conferem confiabilidade e eficiência ao controle e supervisão de processo. Ou seja, na cabine de controle, faz-se necessária a experiência externa à cabine de controle (experiência da área de produção). 0 Gráfico 3 confirma esta hipótese, ao revelar que a totalidade dos operadores consideram sua experiência de "área" como essencial para a aprendizagem do controle.

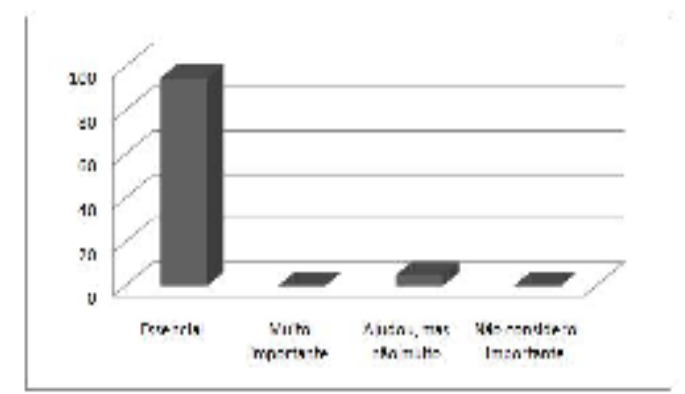

Figura 3 - O quanto o operador considera importante a experiência de "área" no controle de processo via SDCD.

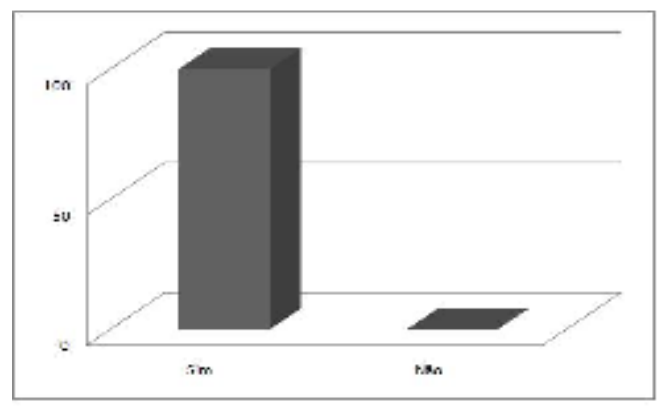

Figura 4 - Se o operador se julga capaz de solucionar os problemas que surgem na cabine de controle. 
As entrevistas em autoconfrontação permitiram confirmar a hipótese de que a experiência de área funciona como uma categoria de desenvolvimento dos sujeitos que supre as lacunas deixadas pelas situações de constrangimento da aprendizagem, o que será explicado mais adiante.

Em síntese, na falta de maior tempo para a dimensão social da aprendizagem (falta de tempo para o contato com os operadores mais competentes e eficientes; não disponibilização, por parte da gerência, deste tempo necessário ao desenvolvimento das competências na interação com o coletivo de trabalho; falta de espaços na organização do trabalho para a aprendizagem cooperativa dos mais novos) é compensada pela aprendizagem adquirida na área de produção e por iniciativa isolada dos aprendizes em sua incipiente atividade na cabine de controle, o que explica porque a experiência de área é considerada essencial para o controle do processo via SDCD (questão 3 do questionário e Gráfico 3). Vejamos um resultado das entrevistas em autoconfrontação:

"Eu hoje uso muito aqui na cabine de controle coisas que eu aprendi na área. Essas coisas ajudaram a gente a aprender mais por conta própria, porque se você depender dos mais experientes você está lascado porque eles não se preocupam com quem tá aprendendo e nem têm tempo pra isso. Assim, a gente tipo que aprende a ligar, na cabeça da gente, o que aparece nas telas com o que a gente viu acontecer lá no chão de fábrica. Isso ajudou muito para que eu aprendesse a controlar o sistema, meio que sozinho, sem muito apoio de ninguém" (operador de cabine da siderurgia).

O Gráfico 4 mostra que operadores dotados desta experiência de área (que ultrapassa os 5 anos de "chão-de-fábrica", segundo as entrevistas em autoconfrontação) sentem-se aptos a solucionar os problemas que surgem na cabine de controle.

Os operadores consideram essa experiência externa à cabine como essencial para o seu desempenho eficaz na cabine de controle. A explicação disso é que, na vivência externa da área de produção, são adquiridos esquemas cognitivos, via assimilação e acomodação (FOLCHER; RABARDEL, 2004), necessários à atividade cognitiva de controle do processo. Ou seja, embora a atividade ocorra num local isolado da área e num ambiente diferente do ambiente da área (sala iluminada, com ar condicionado, confortável, longe da realidade concreta da produção, em atividade que predomina a componente cognitiva da carga de trabalho), mesmo assim, os esquemas demandados para o controle eficiente do processo são aqueles adquiridos pela experiência concreta no ambiente da área (lidando com temperaturas elevadas, em atividades com alta carga física de trabalho, pesadas, desgastantes fisicamente e, em alguns casos, até mesmo insalubres). 


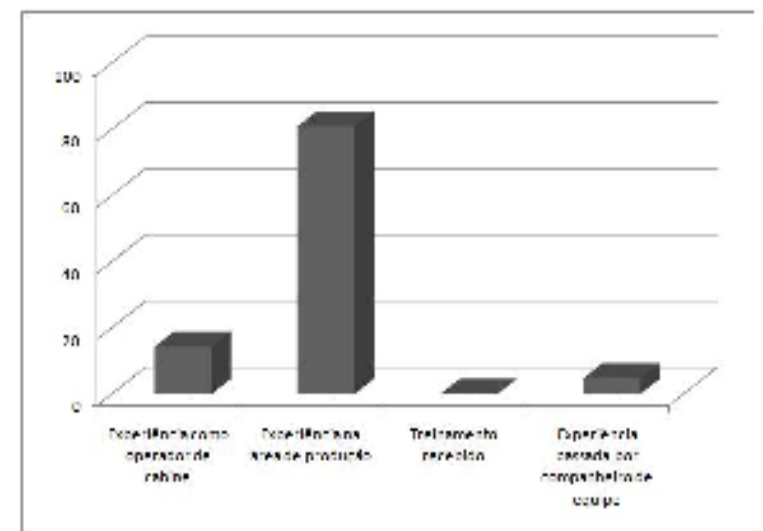

Figura 5 - O que os operadores consideram que mais contribuiu para a sua formação para o controle de processo contínuo.

Isso fica claro quando, no Gráfico 5, e na questão 6 do questionário (além das entrevistas em autoconfrontação), encontramos que o mais importante para a formação destes operadores foi "A experiência que eu adquiri trabalhando na área de produção empresa, em contato com equipamentos, matérias-primas e demais insumos e objetos da produção em situações reais" (questão 6). Neste caso, o item "O treinamento que eu recebi ao entrar no cargo" não aparece nas respostas (questão 6), o que demonstra que a aprendizagem, a formação e o desenvolvimento dos operadores não ocorrem por um processo estruturado e sistematizado dentro da empresa, mas sim num contexto, conforme nossa hipótese, de constrangimento da aprendizagem.

Além disso, pode-se constatar também que a dimensão social da aprendizagem (VYGOTSKY, 1996; CLOT, 2006; WEILL-FASSINA; PASTRÉ, 2004) é fundamental para a formação dos operadores, quando fazem referência às "experiências que meu companheiro de equipe me passou" (questão 6). Embora a porcentagem deste item seja inferior ao "tempo de área", verificamos, nas entrevistas de autoconfrontação, que isso é reflexo dos constrangimentos temporais, organizacionais e relacionais da aprendizagem:

"Assim, importante, importante mesmo seria a gente poder tá mais tempo junto com o pessoal que já era fera no assunto de cabine. Infelizmente, a gente tinha que ficar mendigando a ajuda deles para aprender porque eles também estavam sobrecarregados de serviço e ainda tinham que dar um apoio pra gente. Mas infelizmente eles não conseguiam dar o apoio que a gente precisava" (operador de cabine da siderúrgica).

Nesta verbalização, temos um típico exemplo do que ora denominamos constrangimento relacional da atividade: as relações com os colegas de trabalho mais experientes não são as ideais para o processo de aprendizagem, principalmente devido à sobrecarga de trabalho dos operadores "experts". Isto explica porque, no Gráfico 5 , o item correspondente à parcela social da aprendizagem surja em menor proporção em relação à experiência de área.

Este processo de formação e desenvolvimento, sem uma estruturação prévia, ocorre no cenário que ora denominamos de constrangimento de aprendizagem, conforme já explicado, e caracterizado pelas respostas obtidas para a questão 7 do questionário e mostradas nos Gráficos 6 e 7. Ou seja, o que mais faltou para os operadores (e que gerou constrangimentos em sua formação) foi não ter tido tempo e espaço para ter um contato maior com os operadores que possuíam mais 
experiência e competência (o que também é demonstrado, indiretamente, no Gráfico 5). O que mais gerou constrangimento à aprendizagem, também, foi a ausência de um tempo disponível para aprender o controle de processo junto aos colegas competentes e experientes. Faltou, ainda, disponibilização, por parte da gerência, deste tempo para a aprendizagem em sua dimensão social (CLOT, 2006; VYGOTSKY, 1996; WEILL-FASSINA \& PASTRÉ, 2004).

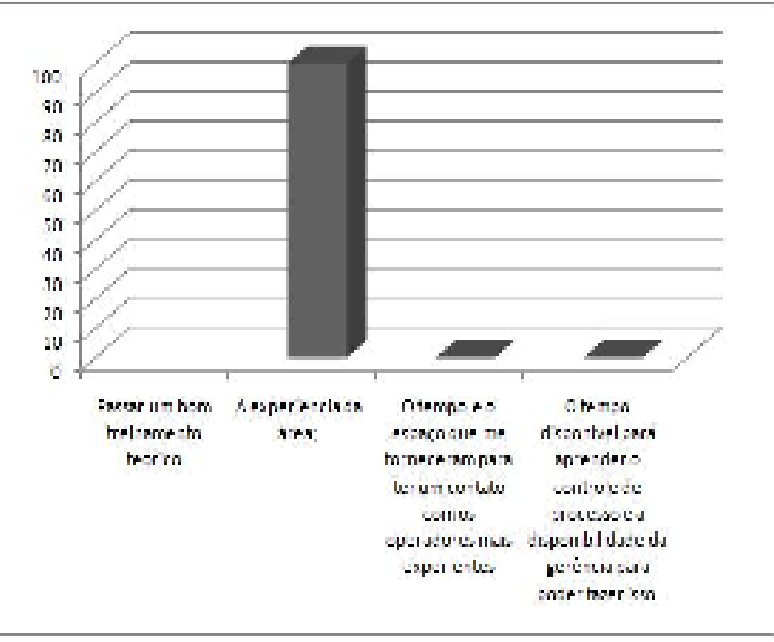

Figura 6 - O que mais contribuiu para a formação dos operadores para a atividade de controle do processo contínuo: a experiência de área. $\mathrm{O}$ que mais faltou para a aprendizagem: tempo e espaço para aprender com os operadores mais experientes.

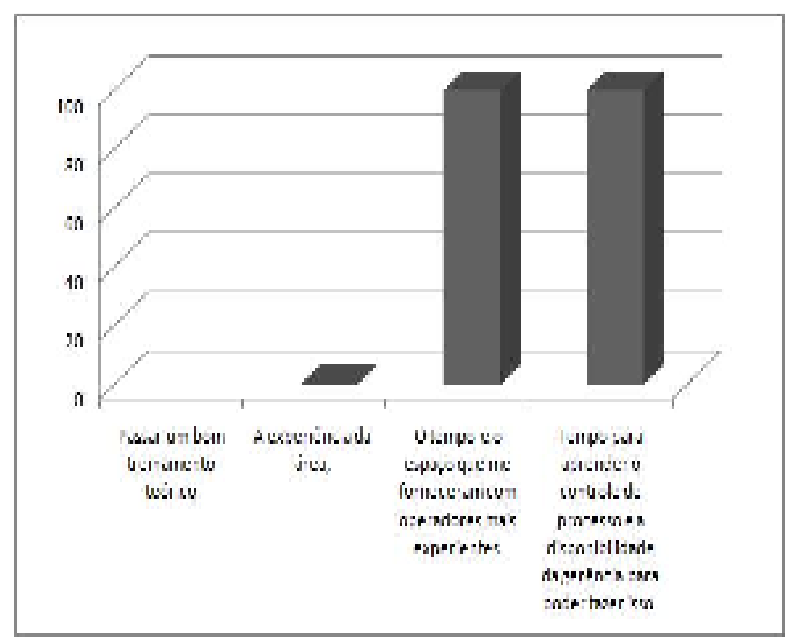

Figura 7 - O que mais fez falta na formação e na aprendizagem dos operadores: tempo e espaço para a aprendizagem com os operadores mais experientes.

Novamente, a experiência de "área" surge como um fator essencial, para suprir os constrangimentos organizacionais e temporais impostos a esta dimensão social da aprendizagem. "Passar por um bom treinamento teórico" sequer aparece nas respostas da questão 7. Já a experiência de longos anos com o próprio sistema automatizado (na cabine de controle) permite a aquisição de uma "expertise" no uso de catacreses, o que explica porque um operador somente consegue operar 0 sistema sozinho, em média, com pelo menos dois anos de contato com o mesmo (segundo os resultados dos questionários e das entrevistas em autoconfrontação).

Mais uma vez, a complexidade surge na pauta dos estudos sobre a aprendizagem do controle de processo contínuo. Segundo os resultados obtidos nas entrevistas em autoconfrontação, nenhum operador aprendeu a atividade e tornouse um "sujeito capaz" (RABARDEL; PASTRÉ, 2005), pronto para lidar com as situações dinâmicas (HOC, 2004), com menos de dois anos de exercício da atividade de controle via SDCD. Para lidar com situações imprevistas, as verbalizações demonstram que o tempo médio varia entre dois e quatro anos de experiência na atividade.

Segundo os resultados obtidos tanto nas entrevistas semi-estruturadas, quanto nas entrevistas em autoconfrontação (AET), a experiência da área foi a categoria mais importante para a formação e a capacitação de um operador de cabine, reforçando a primeira parte da tese ora defendida: a da importância, para as funções cognitivas da cabine de controle, da aquisição de esquemas cognitivos pelo 
contato com o "real da produção" via as interações do sujeito com o ambiente externo à cabine (WEILL-FASSINA; PASTRÉ, 2004; PIAGET, 2003) - interação com seus objetos concretos, numa modalidade de aprendizagem descrita por estes autores como interação sujeito-objeto. Esta experiência de área, ao permitir a interiorização pelos operadores dos esquemas de utilização (FOLCHER; RABARDEL, 2004) supre, conforme a segunda parte da tese ora proposta, as deficiências de uma aprendizagem em sua dimensão social (VYGOTSKY, 1996; CLOT, 2006; WEILL-FASSINA; PASTRÉ, 2004), a qual é constrangida pelas restrições organizacionais, temporais e relacionais impostas ao pleno desenvolvimento dos operadores, por parte da gerência, da hierarquia e da organização do trabalho nas IPC's (Indústrias de Processos Contínuos). A dificuldade de percepção e concepção, por parte dos gestores, do trabalho de controle de processo como uma modalidade de trabalho cooperativo que não se restringe à execução individualizada das tarefas, mas que demanda um conhecimento aprofundado da atividade dos atores e das situações (DANIELLOU; BÉGIN, 2004; DANIELLOU, 2004), acarreta sérias dificuldades para a formação, o desenvolvimento e, enfim, a aprendizagem dos operadores de sua própria atividade.

As experiências de contato com os operadores mais competentes surgem como importante categoria de aprendizagem, pela aquisição de uma competência dada na "zona de desenvolvimento proximal" do sujeito (CLOT, 2006; VYGOTSKY, 1996), via a interação social, descrita por estes autores como uma relação sujeito-sujeito (S-S). No entanto, conforme explicado neste estudo, esta dimensão social da aprendizagem é constrangida pelo modelo de organização do trabalho nas IPC's e pela percepção incorreta sobre a natureza cognitiva e complexa (com suas dimensões coletiva e social) do trabalho dos operadores. Por isso, os operadores dizem que seria fundamental "ter mais tempo com os operadores mais experientes, para poder aprender com eles". Tempo não disponibilizado nem pela hierarquia das IPC's nem pela organização do trabalho, o que, conforme já o dissemos, caracteriza, neste estudo, o que ora denominamos de constrangimentos da aprendizagem (temporal, organizacional e relacional).

A categoria treinamento não surge nas entrevistas, comprovando a hipótese de que não existe, para a atividade de controle de cabine via SDCD, um treinamento premeditado e sistematizado para tal atividade por parte da empresa. A aprendizagem não ocorre por treinamento estruturado e planejado (no sentido comum à literatura), mas sim nos contextos de constrangimento de aprendizagem, ou seja, nos interstícios e porosidades da atividade concreta, nas "brechas" deixadas pela organização do trabalho, sem uma formulação sistemática e estruturada:

"Aprender, cara, o que é isso? Aqui, as coisas não são fáceis pra esse negócio de aprender não. Aqui, se eu aprendi, foi porque eu corri atrás. Fiquei aqui fora do meu horário, já passei quatorze horas dentro desta usina pra tentar pescar alguma coisa e aprender. Já fiquei comendo marmita colado nas telas do sistema vendo o que o outro operador fera fazia. É isso, cara, eu sacrifiquei meus horários de almoço, eu vim pra cá nos dias de folga porque eu tinha que aprender e eu sabia que, mesmo eles fazendo de tudo pra atrapalhar a gente nesse negócio de aprender, se eu não aprendesse rápido, eu estaria fora, cara, eu estaria na rua. Por isso, pra esse negócio de aprender, eu larguei almoço, larguei folga, larguei meu sono, entendeu, larguei minha mulher e filhos em casa, larguei férias, que tive que vender as minhas férias, larguei tudo para aprender, assim, sem ajuda, com meu esforço, que foi assim, é, dando sangue pra aprender. É isso aí" (operador de siderúrgica). 
Nesta verbalização, vemos a presença do constrangimento temporal da aprendizagem: "se eu não aprendesse rápido", e a presença do constrangimento organizacional: "mesmo eles fazendo de tudo pra atrapalhar a gente nesse negócio de aprender".

Segundo os resultados das entrevistas semi-estruturadas e em autoconfrontação, o que mais dificulta a aprendizagem e a formação dos operadores como sujeitos capazes é a falta de tempo (constrangimento temporal) e espaço (constrangimento organizacional) para aprenderem a atividade de controle da cabine. Conforme a tese ora defendida, esta aprendizagem ocorre nas brechas da própria atividade, que jamais se converteu, em sentido pleno, em uma atividade de aprendizagem, mas sim num formato em que é preciso aprender algo complexo "com pouco tempo, sem boa vontade dos colegas e sem o apoio da gerência, que exige que nós devemos aprender rápido, mas não nos dá tempo nem espaço para aprendermos" (operador de cabine da refinaria de petróleo). Ou seja, a organização do trabalho não cria espaço para aprendizagem de um trabalho complexo (constrangimento organizacional), não o favorece, mas exige que o seu resultado ocorra em tempo hábil (constrangimento temporal). A isto atribuímos a noção de constrangimentos de aprendizagem descrita neste texto. Aprender se torna algo mais difícil, pois a atividade de aprendizagem não é vista pela gerência como algo complexo, mas sim como algo simples que pode ocorrer sem um favorecimento de condições ideais para tal. "Quando a gente é novato, a gente fica boiando o tempo todo, sem entender nada do processo e sem ter alguém que fale que está fazendo isso ou aquilo para obter algo assim ou assado. Fica tudo dependendo da força de vontade de quem aprende" (operador de cabine da fábrica de cimento).

"Para aprender é difícil. Se você for um cara mais tímido demora demais para aprender porque o único jeito de entender o processo é perguntando e você fica constrangido de perguntar toda hora. Normalmente até os mais cara-de-pau ficam seis meses voando no trabalho" (operador de cabine da siderúrgica).

Neste cenário de constrangimento da aprendizagem, os operadores dizem que o seu relativo sucesso em aprender a controlar o processo via SDCD se deve, em grande parte, à sua experiência com a área de produção. Esta surge como uma categoria que verdadeiramente supre as lacunas e os constrangimentos de aprendizagem criados pela organização do trabalho. Como problemas mais comuns para a aprendizagem da atividade, surgem, dezenas de vezes nas entrevistas, a falta de tempo (constrangimento temporal), a "falta de consideração da gerência para com quem está aprendendo" (operador de cabine da siderurgia). Por isso, o tempo médio detectado para que o operador consiga trabalhar sozinho na cabine ultrapassa, segundo os resultados, a média de dois anos de "treinamento sem treinamento", ou seja, num contexto de constrangimento da aprendizagem.

\section{CONSIDERAÇÕES FINAIS}

Este estudo detectou que a aprendizagem do operador da cabine de controle ocorre pela ação concreta sobre o real do trabalho (DEJOURS, 1997) e no intercâmbio social com os demais sujeitos da produção. Constatou-se também que não existe uma transmissão de conhecimento na formação dos operadores, mas sim uma construção de saberes do ofício segundo as noções de cognição e ação 
situadas (LAVE, 1996), e de instrumentação da ação (RABARDEL; PASTRÉ, 2005; FOLCHER; RABARDEL, 2004).

Neste percurso teórico e empírico, este artigo buscou responder como se dá esta aprendizagem, difícil pelo caráter tácito anteriormente explicado, num contexto de constrangimentos de aprendizagem que tende a complexificar e dificultar ainda mais o que já é difícil e complexo: aprender a lidar com situações complexas e dinâmicas, em tempo real (HOC, 2004), em curto espaço de tempo e com as dificuldades temporais e organizacionais impostas pela hierarquia e pela organização do trabalho nas IPC's. Esta aprendizagem se dá sem a mediação do saber explícito, formal, porque, dentre outros motivos discutidos aqui, o próprio operador competente não consegue explicitar, formalizar, o seu próprio saber tácito para o aprendiz.

Diversos autores, segundo Jollivet (2003), distinguem o "know-what" ("saber o quê", similar à informação codificada), o "know-how" ("saber-fazer", tácito e contextual), o "know-why" ("saber por quê", de natureza mais científica, geralmente codificado) e o "know-who" ("saber quem"). Segundo esses tipos de saber, as qualidades de acessabilidade, de transferibilidade e de reprodutibilidade são diferenciadas. Boa parte do saber dos operadores de processo contínuo, diríamos mesmo em sua maioria, são do tipo "know-how", tácitos, de difícil acesso, codificação, formalização e transferência. É na partilha de um mundo socialmente compartilhado de trabalho, constituído por outros operadores dotados de "knowhow", que os operadores podem adquirir o saber necessário ao controle do processo na cabine de controle. E foi possível verificar, nesta pesquisa, que esta partilha social é constrangida pela organização do trabalho e pela hierarquia das IPC's. Não há um esquema explícito que possa externalizar este saber tácito vital para o controle de processo com suas situações complexas (LEPLAT; TERSSAC, 1990; LEPLAT, 2004, 2008) e dinâmicas (HOC, 2004).

Os saberes do tipo "know-how" "por seu caráter tácito, contextual e, como veremos, relacional, não podem ser integrados em tal esquema" (JOLLIVET, 2003, p. 92). Segundo o autor, ainda que fosse possível uma completa codificação e formalização do "know-how", haveria um custo (humano) muito elevado ou uma inércia demasiado elevada para a passagem a um conhecimento codificado (JOLLIVET, 2003, pág. 95). A alternativa mais "econômica" é aquela que já fora, há muitos anos, apontada pela ergonomia e pela psicologia do trabalho (CLOT, 2006), qual seja, pelas vias do compartilhamento social. Um operador mais novo somente pode adquirir o "know-how" de um perito ao compartilhar com ele o seu universo social repleto de esquemas operatórios, instrumentos e saberes. "Os autores sustentam que este modo de transmissão repousa bem particularmente sobre atividades de socialização entre os membros, ou seja, sobre a interação informal direta entre indivíduos" (JOLLIVET, 2003, p. 95). Esta interação formal, conforme explicado exaustivamente neste texto, é restringida, constrangida, pela organização do trabalho e pelos diversos tipos de constrangimentos ("impediments", "contraintes") detectados.

Significa, como já bem demonstrado pela ergonomia e pela psicologia do trabalho em sua noção de desenvolvimento (CLOT, 2006) partilhar de um mesmo "gênero" de trabalho, para usar o conceito de Clot (2006), segundo o qual o gênero é um background composto de instrumentos subjetivos, saberes e regras tácitas, encontrados num coletivo de trabalho, que orientam e amparam a ação dos atores da atividade. Nesta imersão no gênero da atividade, em contato com os operadores dotados de "know-how" e de "expertise" é que se dá uma verdadeira aprendizagem 
que, aqui, preferimos usar os termos de Clot (2006), quais sejam, de desenvolvimento cognitivo, no cerne da aprendizagem no trabalho. Neste desenvolvimento, temos uma verdadeira gênese instrumental (RABARDEL; PASTRÉ, 2005), que promove a aquisição de competências (WEILL-FASSINA; PASTRÉ, 2004), de esquemas de utilização e a instrumentação da ação (FOLCHER; RABARDEL, 2004).

De qualquer modo, temos um fenômeno interessante que grosseiramente podemos entender, nesse intercâmbio entre os atores da produção, como uma "transmissão sem transmissão" de saber tácito para saber tácito (JOLLIVET, 2003). O operador não aprende pela recepção passiva de instruções, normas e regras de controle eficiente de processo, mesmo porque a eficiência depende de um saber tácito que não se encontra nas instruções, nem nas normas e regras do trabalho prescrito.

A resposta a isso está no fato de que há, então, no desenvolvimento de um sujeito capaz, uma centralidade da relação de interação entre indivíduos (JOLLIVET, 2003, p. 95), que deveria ser favorecida pelas empresas e não restringida e constrangida, uma vez que a aprendizagem é sempre conduzida por uma atividade de natureza interativa no interior da atividade de trabalho, dotada de um gênero (CLOT, 2006). É, portanto, na confrontação com os pares, na comunicação interativa, na socialização, mediada pelos instrumentos de trabalho, que ocorre a gênese da aprendizagem, quer a compreendamos como um desenvolvimento (à maneira de Clot (2006)), quer a vejamos como uma gênese instrumental e aquisição de esquemas operatórios para ação eficaz (conforme Rabardel \& Pastré (2005)).

\section{REFERÊNCIAS}

BECKER, H. S. Métodos de pesquisa em ciências sociais. São Paulo: Hucitec, 1997.

CLOT, Y. A função psicológica do trabalho. Petrópolis: Vozes, 2006.

DANIELLOU, F. L'ergonomie dans la conduite de projets de conception de systèmes de travail. In: FALZON, P. Ergonomie. Paris, PUF (Presses Universitaires de France), p. 359-373, 2004.

DANIELLOU, F.; BÉGUIN, P. Méthodologie de l'action ergonomique: approches du travail réel. In: FALZON, P. Ergonomie. Paris, PUF (Presses Universitaires de France), p. 335-358, 2004.

DEJOURS, C. O fator humano. Rio de Janeiro: FGV, 1997.

FOLCHER, V.; RABARDEL, P. Hommes, artefacts, activités: perspective instrumentale. In: FALZON, P. Ergonomie. Paris, PUF (Presses Universitaires de France), p. 251-268, 2004.

GALVÃO, A. P.; SILVA, G.; COCO, G. Introdução: conhecimento, inovação e redes de redes. In: GALVÃO, A. P.; SILVA, G.; COCCO, G. Capitalismo cognitivo: trabalho, redes e inovação. Rio de Janeiro: DP\&A, p. 7-14, 2003. 
GUÉRIN, F. et al. Compreender o trabalho para transformá-lo: a prática da Ergonomia. São Paulo: Edgard Blücher, 2002.

HOC, J. M. Vers une coopération homme-machine en situation dynamique. In: FALZON, P. Ergonomie. Paris, PUF (Presses Universitaires de France), p. 269-283, 2004.

JOLLIVET, P. NTIC e trabalho cooperativo reticular: do conhecimento socialmente incorporado à inovação sociotécnica. In: GALVÃO, A. P.; SILVA, G.; COCCO, G. Capitalismo cognitivo: trabalho, redes e inovação. Rio de Janeiro: DP\&A, p. 83-107, 2003.

LAVE, J. The practice of learning. In: CHAIKLIN, S.; LAVE, J. (Eds). Understanding practice: perspectives on activity and context. New York: Cambridge University Press, p. 126-149, 1996.

LEPLAT, J. Regards sur l'activité en situation de travail. Paris: PUF, 1997.

LEPLAT, J. L'Analyse du travail en psychologie ergonomique. Paris: Octares, 1999.

LEPLAT, J. Aspectos da complexidade em ergonomia. In: DANIELLOU, F. A Ergonomia em busca de seus princípios. São Paulo: Edgard Blücher, p. 57-7, 2004.

LEPLAT, J. Reperes pour l'analyse de l'activite en ergonomie. Paris: PUF, 2008.

LEPLAT, J.; TERSSAC, G. Les Facteurs Humains de la Fiabilite dans les Systemes Complexes. Marseille: Edition Octarès, 1990.

PIAGET, J. Biologia e conhecimento. Petrópolis: Vozes, 2003.

POLANYI, M. Tacit dimension. New York: Peter Smith, 1983.

POLANYI, M. Personal knowledge. London: Routledge, 1998.

POZZO, J.I. Teorias cognitivas da aprendizagem. Porto Alegre: Artes Médicas, 2002.

RABARDEL, P.; PASTRÉ, P. Modèles du sujet pour la conception: dialectiques, activités, développement. Paris: Octarès Éditions, 2005.

SCHWARTZ, Y. Os Ingredientes da Competência: um exercício necessário para uma questão insolúvel. Educação \& Sociedade. v. 2. n. 65. p. 101-139. Dezembro, 1998.

THIBAULT, J. F. Contribuição da ergonomia em projetos de concepção e implantação de SDCD. In: Duarte, F. (Org.). Ergonomia e projeto na indústria de processo contínuo. Rio de Janeiro: Lucerna (UFRJ), 2002.

VASCONCELOS, R. C.; LIMA, F. P. A.; CAMAROTTO, J. A.; ABREU, A. C. M. S.; FILHO, A. O. S. C. Aspectos de complexidade do trabalho de coletores de lixo 
domiciliar: a gestão da variabilidade do trabalho na rua. Gestão \& Produção. v. 15. n. 2. p. 407-419. Agosto, 2008.

VYGOTSKY, L. S. Teoria e método em psicologia. São Paulo: Martins Fontes, 1996.

WEILL-FASSINA, A.; PASTRÉ, P. Les compétences professionnelles et leur développement. In: FALZON, P. Ergonomie. Paris, PUF (Presses Universitaires de France), p. 213-231, 2004.

WISNER, A. Por dentro do trabalho: Ergonomia - método e técnica. São Paulo: FTDOboré, 1987. 